\title{
Racial and Ethnic Health Disparities in TRICARE
}

\author{
June 2009
}

Presentation to the AcademyHealth Conference Ann D. Bagchi Eric Schone Patricia Collins Higgins Elder Granger S. Ward Casscells Thomas Croghan 


\section{Background}

- Health disparities a serious problem in the U.S.

- Federal government major provider and financer of health care for minority populations

- TRICARE - the DoD's health care program

- Those entitled to benefits during or consequent to service

- Families and survivors of these members

- Coverage provided through 5 separate programs

- Equity in health care part of the larger DoD mission to ensure "equality of treatment and opportunity" 


\section{Study Motivation}

- Prior studies examine disparities in other federallyfunded systems of care

- Many have found fewer disparities

- Few studies have examined the TRICARE program

- Very diverse population

- Common benefits removes some variation in benefit

- Determine whether patterns of disparities observed in U.S. healthcare system are present in TRICARE 


\section{Data}

- 2007 Health Care Survey of DoD Beneficiaries (HCSDB)

- Quarterly survey of active duty military, retirees, and family

- Stratified random sample of 50,000 adult beneficiaries

- Overall response rate $25.1 \%$ but wide variation

- Active duty: $15.6 \%$

- Retirees aged 65 or older: $77 \%$

- Sample sizes increased to account for survey nonresponse

- Weights included for nonresponse and sampling design 


\section{Methods}

- Descriptive analysis comparing 2007 HCSDB with:

- 2006 National CAHPS ${ }^{\circledR}$ Benchmarking Database (NCBD) 3.0

- Used to compare health status, access, and satisfaction

- AHRQ's 2007 National Healthcare Disparities Report (NHDR)

- Used to compare data on use of preventives services

- Stratifying variables

- Race/ethnicity

- Active duty status 


\section{Outcome Measures}

- Health status

- Self rated health

- Access to care

- Ability to find an acceptable personal doctor or nurse

- Ability to see a specialist when needed

- Satisfaction with care

- Doctor listened to patient's concerns

- Doctor was courteous and respectful

- Use of preventive services

- Smoking cessation counseling

- Colon cancer screening

- Pap smear

- Mammography

- Annual flu shot 


\section{Statistical Analyses}

- Two sets of comparisons for each measure

- Blacks and Hispanics versus whites within category

- Magnitude of disparity versus civilian health plans

- t-tests of differences in proportions

- Bonferroni adjustment for multiple comparisons

- Test statistics and standard errors estimated to account for complex sample design 


\section{Sociodemographics}

\begin{tabular}{|l|c|c|c|}
\hline Variable & White & Black & Hispanic \\
\hline Age & & & \\
$\quad$ 18-34 & 27.0 & 26.1 & 39.9 \\
$\quad$ 35-64 or older & 62.7 & 69.1 & 56.0 \\
& 10.2 & 4.8 & 4.1 \\
Male & & & \\
Education & 49.9 & 52.6 & 45.4 \\
$\quad$ High school & & & \\
$\quad$ Some college & 20.6 & 20.4 & 24.0 \\
$\quad$ College grad & 40.0 & 50.5 & 47.4 \\
Duty status & 39.3 & 29.2 & 28.7 \\
$\quad$ Active duty & & & \\
$\quad$ Retirees/survivors & 54.5 & 57.0 & 65.6 \\
\hline
\end{tabular}




\section{Health Status}

\section{\% Reporting Good/Excellent Self-rated Health}

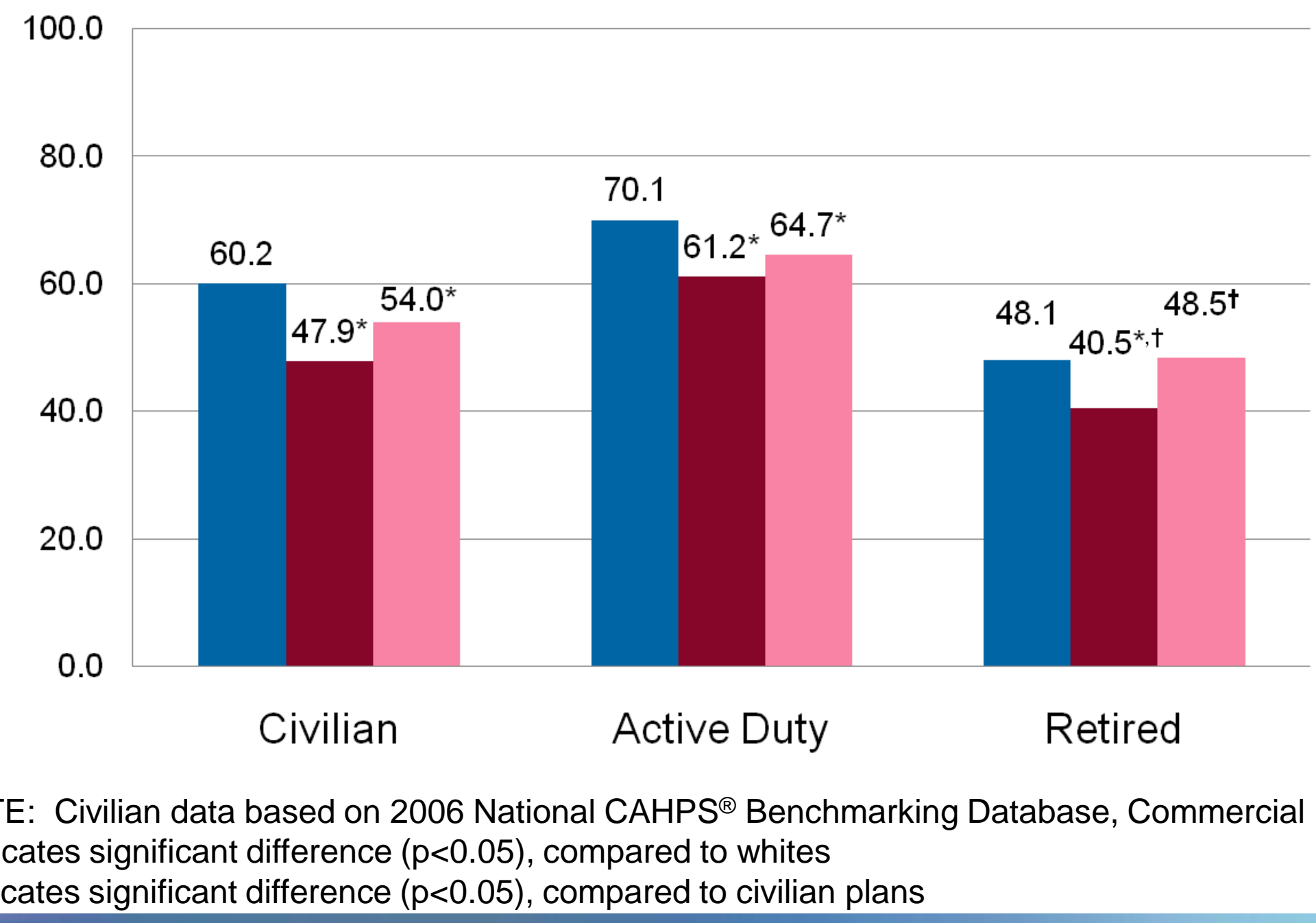

NOTE: Civilian data based on 2006 National CAHPS ${ }^{\circledR}$ Benchmarking Database, Commercial *Indicates significant difference $(p<0.05)$, compared to whites

tIndicates significant difference $(p<0.05)$, compared to civilian plans 


\section{Access to Care}

\section{$\%$ Reporting No Problem Seeing a Specialist}

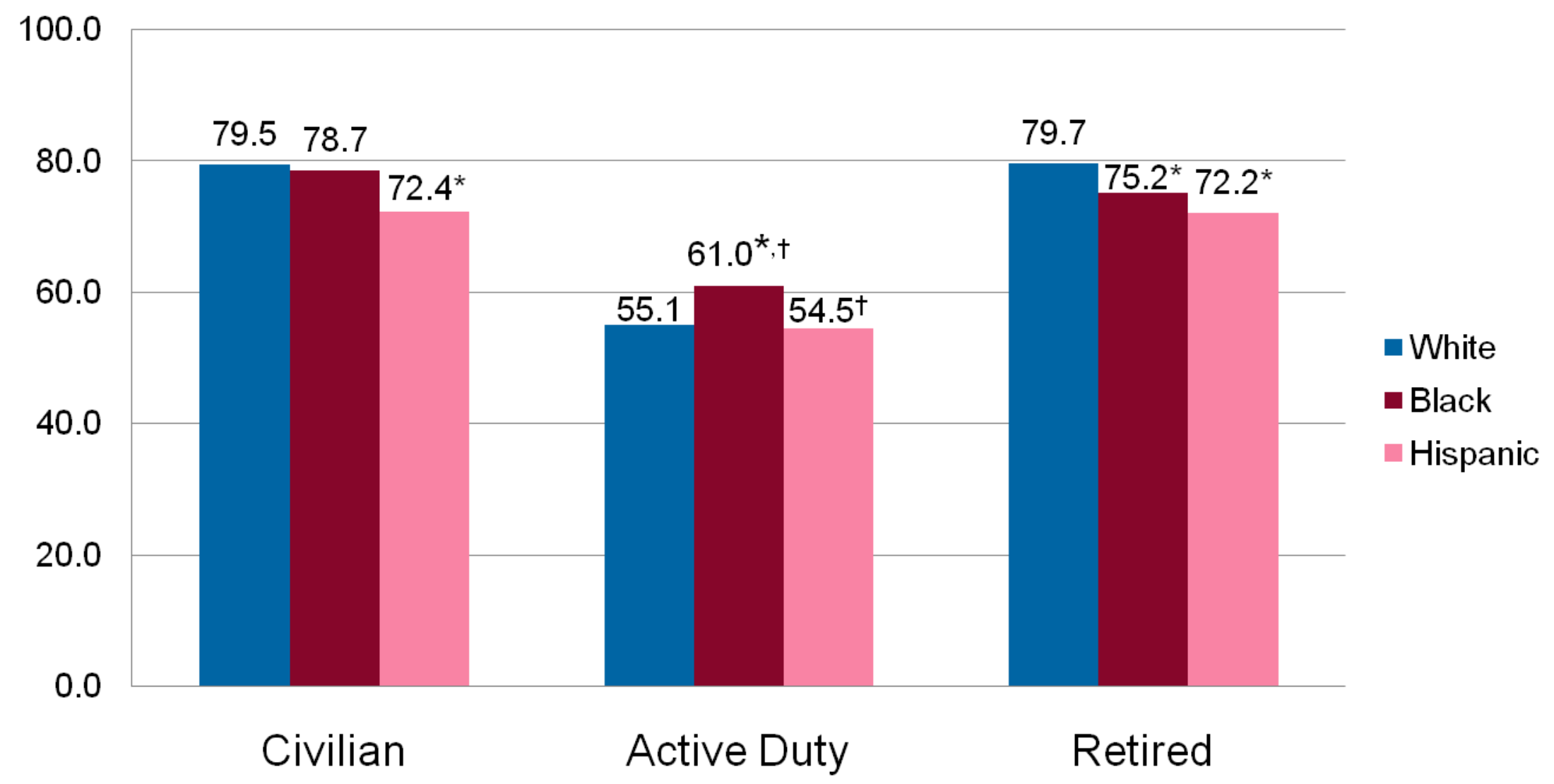

NOTE: Civilian data based on 2006 National CAHPS ${ }^{\circledR}$ Benchmarking Database, Commercial *Indicates significant difference $(p<0.05)$, compared to whites †Indicates significant difference $(p<0.05)$, compared to civilian plans 


\section{Satisfaction with Care}

\section{\% Saying Doctor Showed Respect}

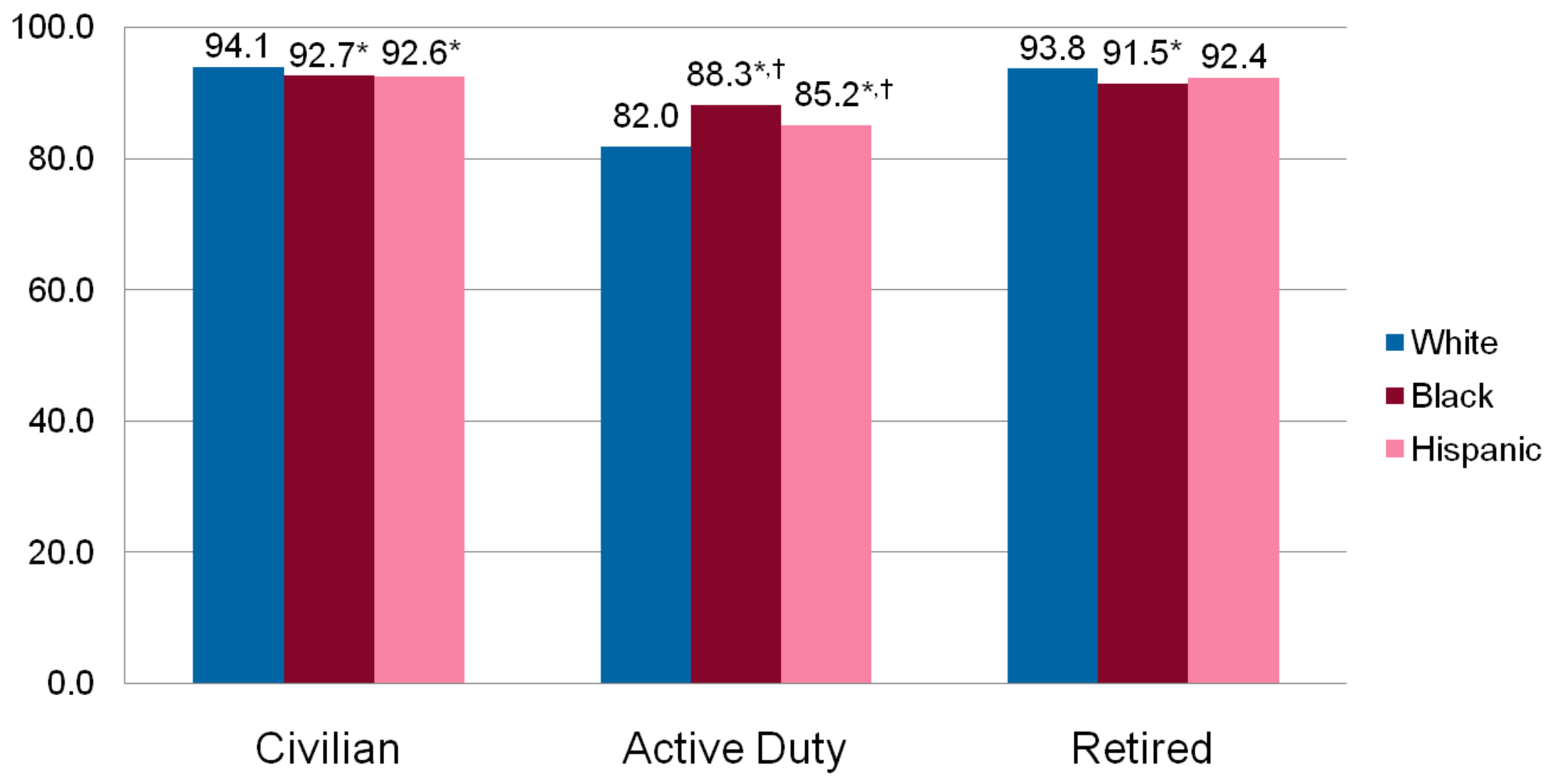

NOTE: Civilian data based on 2006 National CAHPS ${ }^{\circledR}$ Benchmarking Database, Commercial *Indicates significant difference $(p<0.05)$, compared to whites tIndicates significant difference $(p<0.05)$, compared to civilian plans 


\section{Use of Preventive Services}

\section{\% Receiving Smoking Cessation Counseling}

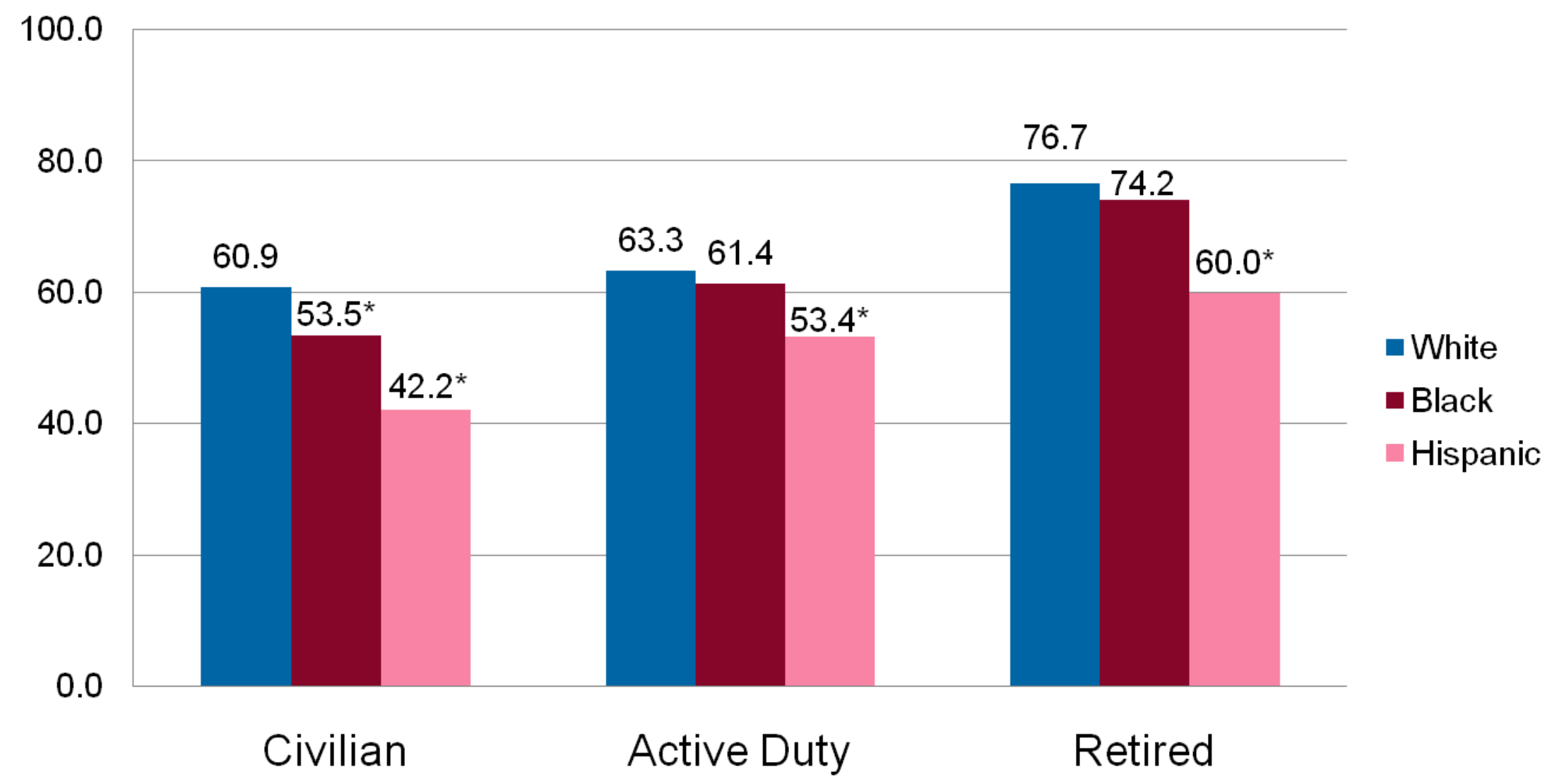

NOTE: Civilian data based on 2007National Healthcare Disparities Report *Indicates significant difference $(p<0.05)$, compared to whites †Indicates significant difference $(p<0.05)$, compared to civilian plans 


\section{Use of Preventive Services}

\section{\% Receiving Pap Smear}

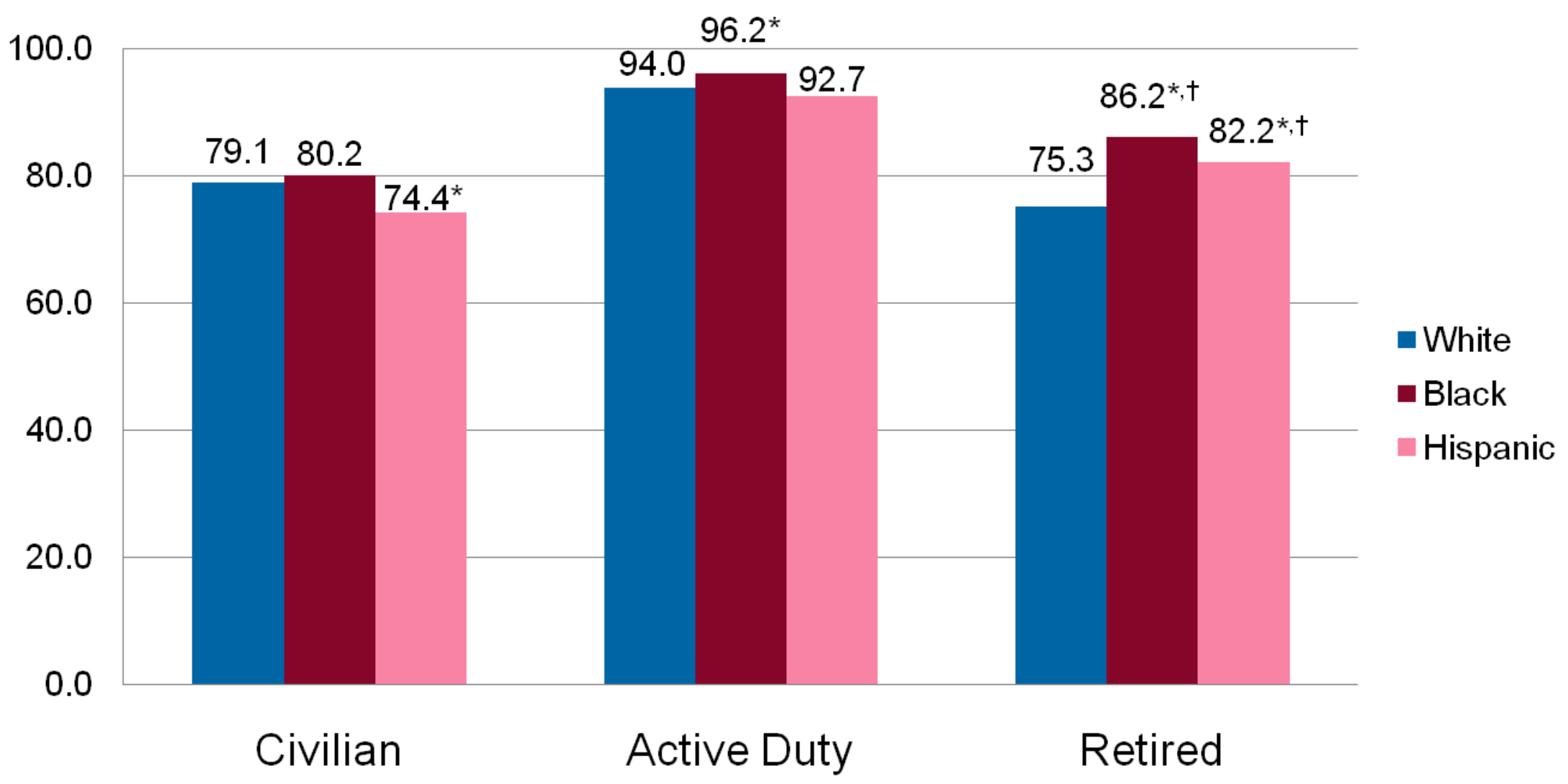

NOTE: Civilian data based on 2007National Healthcare Disparities Report *Indicates significant difference $(p<0.05)$, compared to whites †Indicates significant difference $(p<0.05)$, compared to civilian plans 


\section{Discussion}

- Some disparities exist in the TRICARE program

- Disparities are smaller or reversed from those in civilian plans

- Findings could help guide health care reform

- Are coverage and access sufficient to eliminate disparities?

- Cultural aspects of DoD and MHS

- Need for more research on disparities in TRICARE

- Better collection of data on race/ethnicity

- Link HSCDB with claims to enable multivariate models

- Look at treatments and outcomes 